\title{
MODIFIED COMPLETE DENTURE PROSTHESIS TO SUPPORT LIP AND IMPROVE SPEECH IN COMPLETELY EDENTULOUS PATIENTS WITH NEUROLOGICAL PROBLEM-A CASE REPORT
}

Sunny Panthi, ${ }^{1}$ Mohit Kamra, ${ }^{2}$ Amrit Khosla, ${ }^{2}$ Atulya Sharma, ${ }^{3}$ Swati Kapoor ${ }^{2}$

${ }^{1}$ Department of Prosthodontics, MN DAV Dental College and Hospital, Solan, Himachal Pradesh, India

${ }^{2}$ Department of Prosthodontics, Bhojia Dental College and Hospital, Baddi, Himachal Pradesh, India

${ }^{3}$ Department of Prosthodontics, Dental Clinic, Nangal, Punjab, India

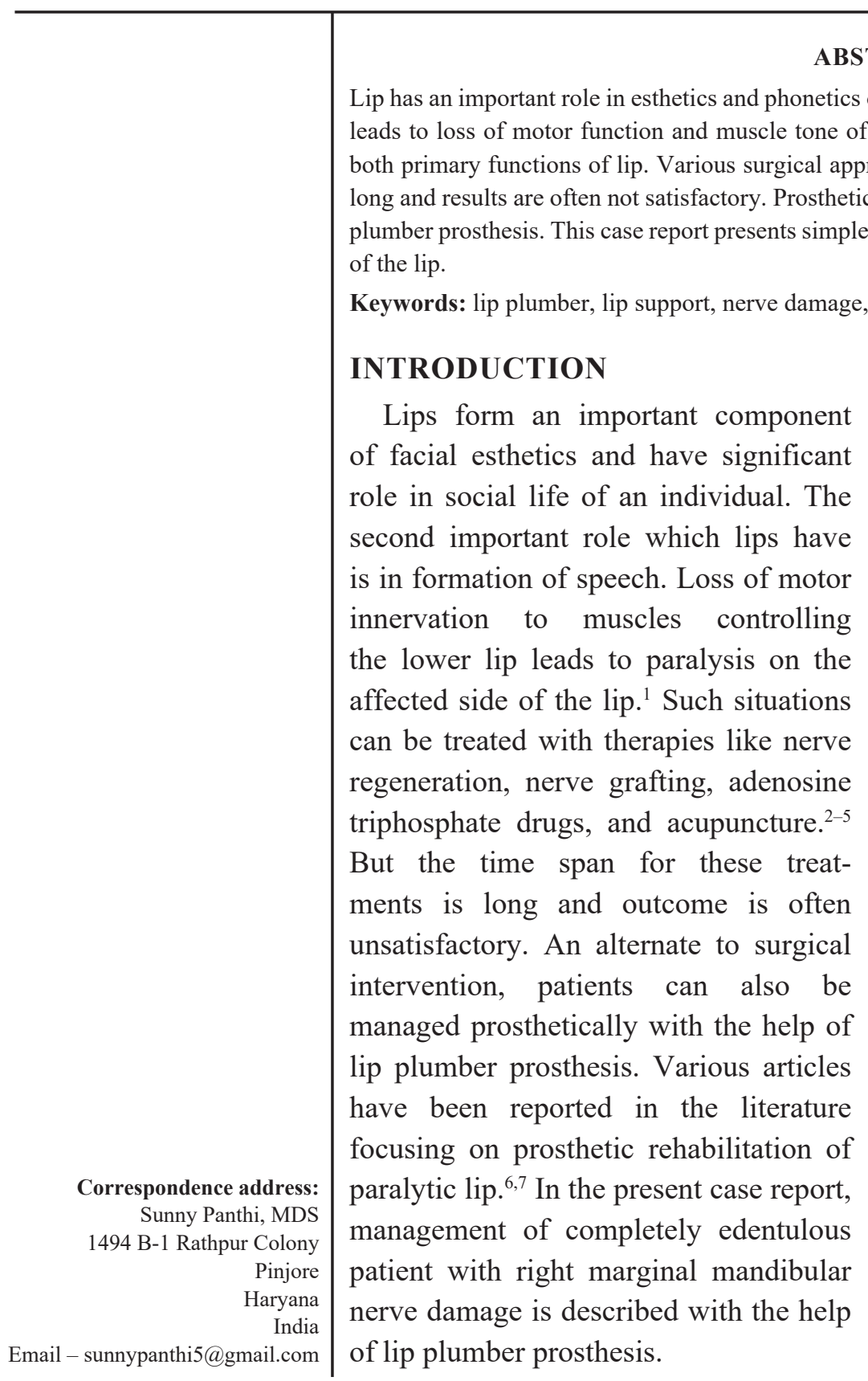

\section{ABSTRACT}

dividual. Damage to marginal mandibular nerve ed side of lip. Eventually, it leads to loss of the treatment time is accurate method to restore the harmonious relation ysis

\section{CASE REPORT}

A 58-year-old male patient was referred to the Department of Prosthodontics G.D.C. Amritsar for oral rehabilitation. On examination, patient had completely edentulous maxillary and mandibular ridges. Extraoral examination revealed loss of motor function and muscle tone in right lower lip with the deviation of lip toward left (Figure 1). Patient had a history of trauma and mandibular setback surgery. There was also a loss of retromolar area in right mandibular region with damage to right marginal mandibular nerve. As a result, the right lower lip was paralyzed giving unesthetic appearance to the patient. Treatment plan was made keeping in view the functional and esthetic requirement of patient. It was planned to give upper and lower complete denture with fixed lip support prosthesis to prevent lip biting and meet phonetic requirement of the patient.

Maxillary and mandibular initial impressions were made with impression 


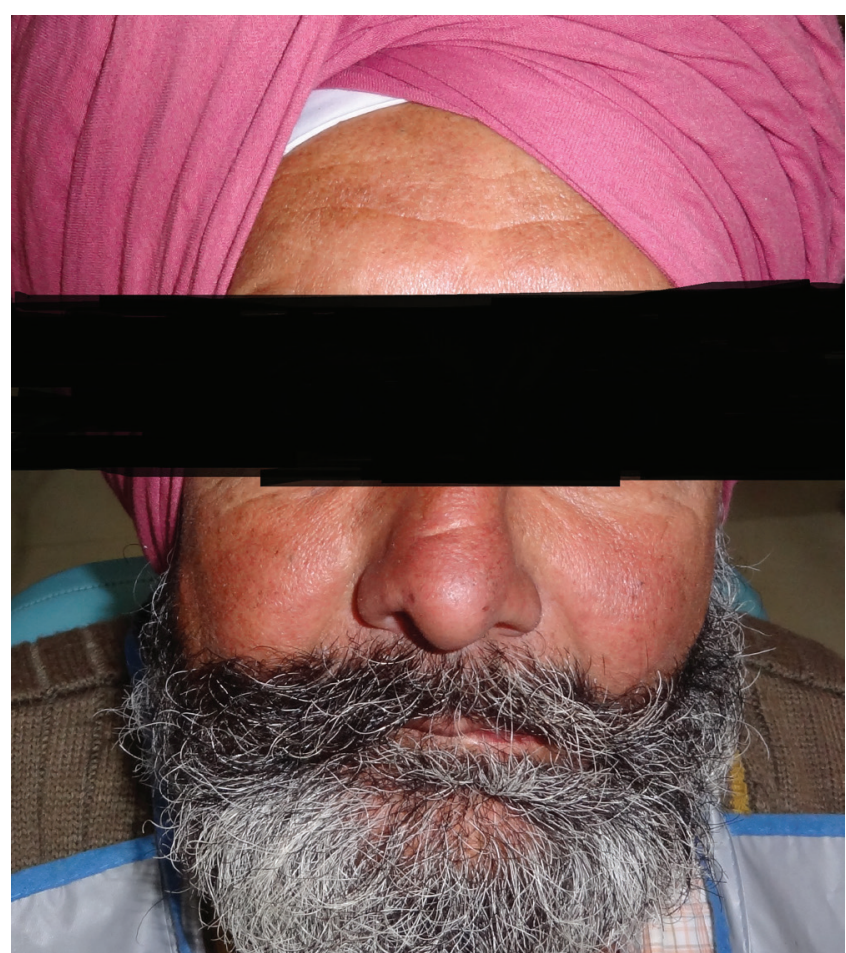

Figure 1: Preoperative view of the patient.

compound. Autopolymerizing resin custom trays with spacer were used to make final impression with ZOE. Jaw relations were recorded and try-in was done for patient. No significant improvement was seen in speech and added to that there was right lip biting (Figure 2). Conventional complete denture was made and adjusted in patient's mouth. After insertion of denture, modeling wax pattern was made on lower denture to support lip and prevent lip biting. Modeling wax was molded and shaped within functional and esthetic limits. Try-in of prosthesis was done. Addition of silicon putty index was made on molded wax. Wax was then removed and roughening of denture was done in area of wax pattern. Separating media was applied on areas adjoining the index to prevent adhesion of self-cure resin. Clear selfcure acrylic resin was filled inside the index. After curing of cold cure resin, finishing and polishing was done (Figure 3). Patient was instructed on the use of lip support/lip plumber prosthesis. It significantly improved the esthetics by recreating the lost contour of lip and also prevented lip biting between the denture teeth (Figure 4). Recall appointment was scheduled after 1 day, 7 days, 1 month, and 6 months.

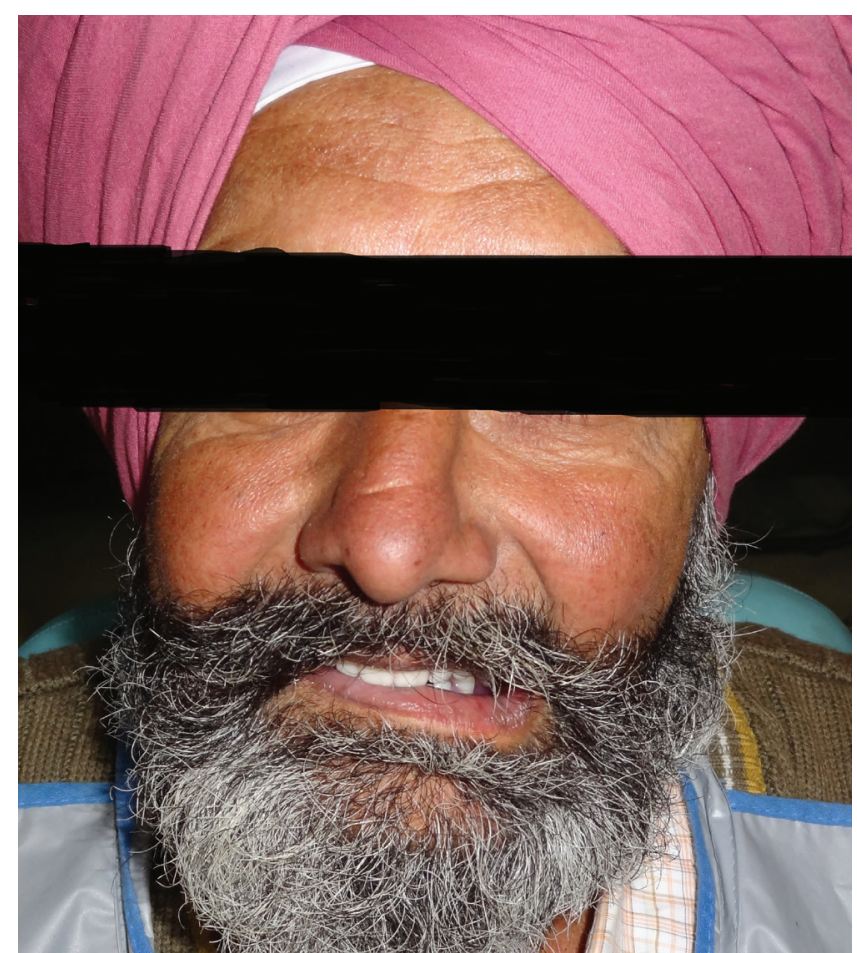

Figure 2: Patient experiencing lip biting with original denture.

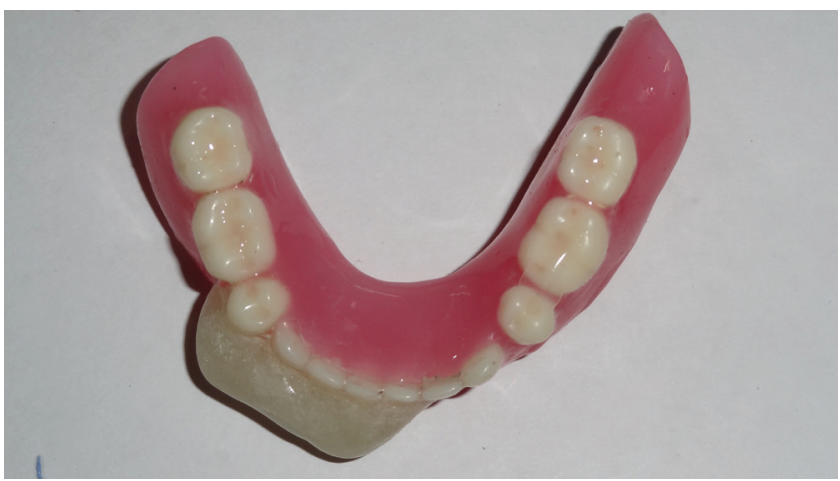

Figure 3: Lip plumber prosthesis.

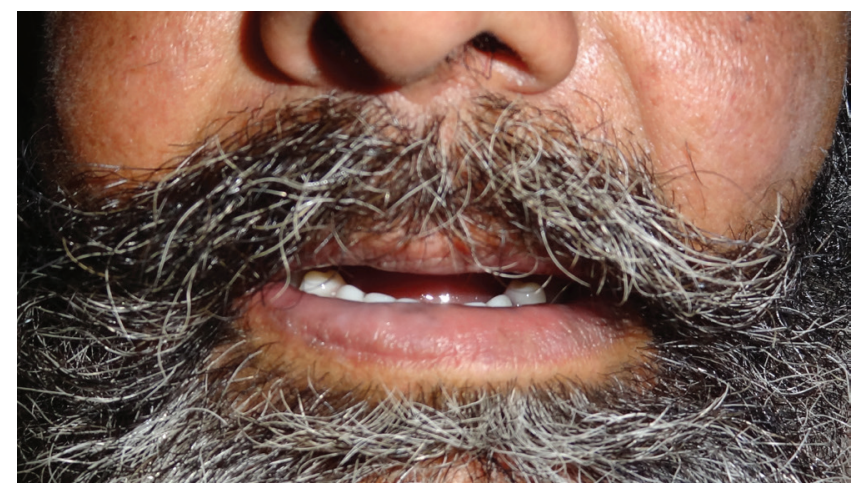

Figure 4: Postoperative view of the patient. 


\section{DISCUSSION}

Many case reports have advocated the use of lip and cheek plumber prosthesis with great degree of success. ${ }^{8,9}$ Simple yet accurate method for the fabrication of lip plumber prosthesis is presented in present case report. Action of tongue, cheek, and lip on complete denture should be accurately examined for the success of prosthesis. Use of lip plumber is advocated within functional limit of acting muscles. Properly fabricated lip support prosthesis will highly improve esthetics and prevent lip biting in patients with neurological defects.

Patient's acceptance of treatment by lip plumber was positive and had shown significant improvement in speech and mastication during follow-up appointments.

\section{CONCLUSION}

This case report describes an effective, simple, and noninvasive procedure to maintain function and esthetic in edentulous patients with marginal mandibular nerve damage resulting in loss of lip support. Customized wax pattern on final denture gives accurate guide about location and extend of required lip support. Lip support prosthesis provides significant improvement in contour and function in edentulous patients with lip paralysis.

\section{REFERENCES}

1. Beumer J, Marunick MT, Curtis TA, Roumanas E. Acquired Defects of the Mandible. St. Louis: Ishiyaku EuroAmerica; 1996:113-223

2. Jones JK, Van Sickels JE. Facial nerve injuries associated with orthognathic surgery: a review of incidence and management. J Oral Maxillofac Surg 1991;49(7):740-744

3. Choi D, Dunn LT. Facial nerve repair and regeneration: an overview of basic principles for neurosurgeons. Acta Neurochir (Wien) 2001;143(2):107-114

4. McCabe BF. Facial nerve grafting. Plast Reconstr Surg 1970;45(1):70-75

5. Conley J. Treatment of facial paralysis. Surg Clin North Am 1971;51(2):403-416

6. Folkins JA, MacLeod WD. An intraoral appliance for facial paresis. Can Med Assoc J 1953;69(6):632-633

7. Lazzari JB. Intraoral splint for support of the lip in Bell's palsy. J Prosthet Dent 1955;5:579-581

8. MukohyamaH,Kadota C,Ohyama T, TaniguchiH.Lip plumper prosthesis for a patient with a marginal mandibulectomy: a clinical report. J Prosthet Dent 2004;92(1):23-26

9. Hatjigiorgis CG, Martin JW. An interim prosthesis to prevent lip and cheek biting. J Prosthet Dent 1988;59(2):250-252 